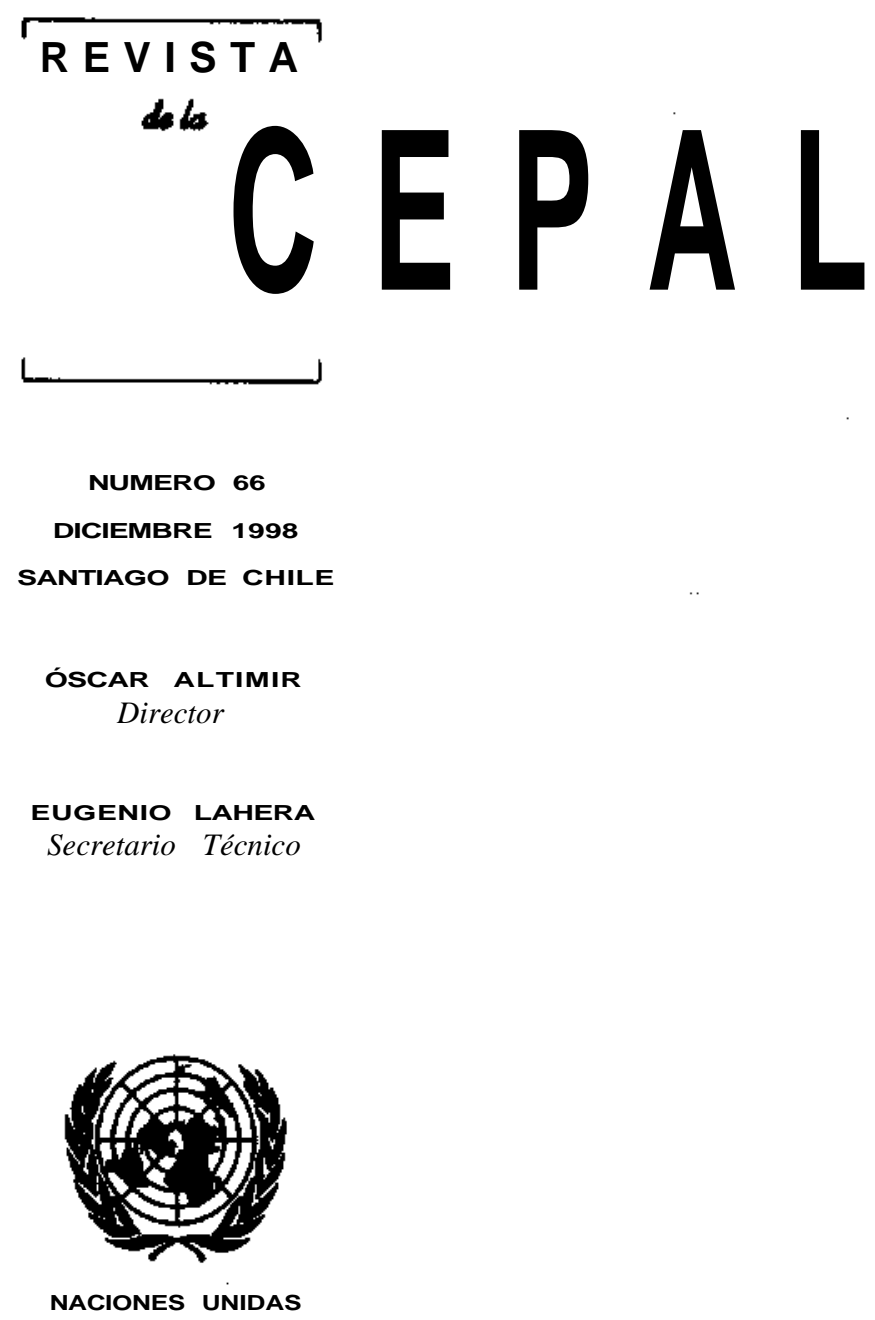


Más allá del Consenso de Washington: una visión desde la CEPAL

José Antonio Ocampo

La economía de Cuba

David Ibarra y Jorge Máttar

La educación en América Latina: la demanda y la distribución importan

Nancy Birdsall, Juan Luis Londoño y Lesley O'Connell

Determinantes de la desigualdad entre los hogares urbanos

Luis Felipe Jiménez L. y Nora Ruedi A.

Los compromisos de gestión en salud de Costa Rica con una perspectiva comparativa

Ana Sojo

Una estrategia de desarrollo a partir de complejos productivos en torno a los recursos naturales

Joseph Ramos

Grandes empresas y grupos industriales latinoamericanos

Celso Garrido y Wilson Peres

Entre el control político y la eficiencia: evolución de los derechos de propiedad agraria en México

Gustavo Gordillo, Alain de Janvry y Elizabeth Sadoulet

Los aranceles y el Plan Real de Brasil

Renato Baumann, Josefina Rivero y Yohana Zavattiero

Publicaciones recientes de la CEPAL 


\section{Entre el control político y la eficiencia: evolución de los derechos de propiedad agraria en México}

\section{Gustavo Gordillo \\ Organización de las}

Naciones Unidas para la

Agricultura y la

Alimentación (FAO).

Roma

\section{Alain de Janvry y} Elizabeth Sadoulet

Universidad de California, Sede de Berkeley
Fruto de la revolución mexicana, el ejido fue creado con múltiples propósitos: lograr el control político del campesino, representarlo en sus relaciones con el Estado y prestar asistencia para la producción de los minifundistas. Estos múltiples objetivos, al comienzo conciliables y base de una fructuosa etapa de crecimiento económico y de mejoramiento del bienestar, fueron haciéndose cada vez más contradictorios, lo que precipitó una crisis de grandes proporciones tanto en la producción como en el bienestar rurales. Ya en 1992, año en que se enmendó el artículo 27 de la Constitución de 1917, el ejido se caracterizaba por una fuerte intervención estatal en sus asuntos internos, incluso en sus mecanismos de toma de decisiones, en las condiciones de acceso a los recursos públicos y en la administración del sistema de bienestar rural. Fue esta misma decadencia del sistema del ejido, en el contexto global de la liberalización política y económica, que aconsejó las profundas reformas iniciadas por el Presidente Salinas. Entre las reformas figuran la redefinición de las relaciones entre el Estado y las unidades familiares del sector ejidal, la reestructuración de las instituciones públicas que atienden al sector, la reforma del marco jurídico que regula el acceso a la tierra y la modificación de ios instrumentos de la política agraria. En el presente artículo describiremos el impacto inicial de estas reformas sobre el sector ejidal. 


\section{El medio rural como "menor de edad": el conflicto de intereses, 1910-1940'}

El contrato social que garantizó la paz y la estabilidad en el campo durante la mayor parte de los últimos cincuenta años y que permitió institucionalizar el conflicto luego de 25 años de revolución armada, se concretó en el gobierno del Presidente Cárdenas. ${ }^{2}$ Durante ese gobierno, el levantamiento campesino fue derrotado militarmente, sus demandas sociales y su programa político fueron asimilados en el marco constitucional del nuevo régimen, sus líderes fueron reprimidos o integrados al sistema político, los otros poderes que disputaban la hegemonía del Estado en el sector rural — los terratenientes y el clero- fueron desarticulados políticamente, y el nuevo sistema institucional se consolidó sobre la base de una complementación corporativa de los organismos estatales y las organizaciones nacionales de agricultores.

Las disposiciones básicas del artículo 27 de la Constitución se redactaron bajo la influencia de una fuerte corriente intelectual, que ya había comenzado a perfilarse en los últimos días de la dictadura de Porfirio Díaz. ${ }^{3}$ Una de las principales premisas de este movimiento era su repudio al papel conservador que desempeñaba la hacienda. ${ }^{4}$ La distribución de la tierra se consideraba en esencia como una política de modernización, que tenía por principal objetivo eliminar los obstáculos que se oponían al desarrollo del capitalismo y al fortalecimiento del mercado interno. Siendo así, se creía que la reforma agraria por sí sola crearía una clase social capaz de engendrar el prototipo de la modernidad: el agricultor empresario.

Es probable que el postulado más importante de esta corriente intelectual haya sido su "estatolatría", al

\footnotetext{
D Este artículo corresponde a una ponencia redactada para su presentación en la vigesimotercera Conferencia Internacional sobre Economía Agrícola, Sacramento (California), agosto de 1997.

1 Basado en Gordillo, 1988 b.

2 El Presidente Lázaro Cárdenas gobernó México de 1934 a 1940. En Córdova, 1973, se presenta una descripción detallada sobre ese período.

3 Este movimiento intelectual ha sido analizado por Krauze, 1971 y Córdova , 1973. Uno de los principales representantes de este movimiento fue Andrés Molina Enriquez.

4 Véase Orozco, 1895, en el que se exponen los principales argumentos sobre el rol conservador de las haciendas en México.
}

considerar al Estado como agente social por excelencia, tanto en una sociedad mexicana reorganizada como en la promoción de su desarrollo económico. El artículo 27 de la Constitución surgida del Congreso Constituyente de 1917 estipula que el Estado es creador de propiedad - lo que contradice la doctrina tradicional del derecho natural- ya que se establece que la propiedad de las tierras y las aguas corresponde originariamente a la Nación, "la cual ha tenido y tiene el derecho de transmitir el dominio de ellas a los particulares constituyendo la propiedad privada". Asimismo, se indica que la Nación "tendrá en todo tiempo el derecho de imponer a la propiedad privada las modalidades que dicte el interés público".

Aunque en la Constitución se estipula que el Estado actúa en toda oportunidad como representante de la Nación, por tratarse de un régimen presidencial, en la práctica se delega esta función en el Ejecutivo, y por lo tanto, también la de creación de propiedad privada.

En el artículo 27 se reconocen tres categorías de propiedades rurales: las pequeñas propiedades agrícolas, las comunidades y los ejidos; estas dos últimas reciben trato especial. En la Constitución se reconoce debidamente el daño provocado a las comunidades indígenas durante el período de reformas liberales de la segunda mitad del siglo XIX, debido a la aplicación del principio según el cual todos los ciudadanos tienen igual capacidad jurídica; para indemnizarlos por el daño sufrido, se dispone que todos los litigios por distribución o restitución de tierras y todos los casos de solución de controversias con los indígenas deberán ser conocidos por tribunales administrativos, no judiciales, "para que pudiera, discrecionalmente, apreciarse las circunstancias especiales que pudieran provenir de la falta de capacidad de los pueblos... De no ser así, los juicios administrativos de que se trata, que son administrativos precisamente para ser discrecionales, son reducidos por este o por aquel medio legal a convertirse en juicios de estricto derecho, será inútil seguirlos; puede decirse por anticipado que no habrá dotación o restitución que no venga a ser totalmente deshecha por la habilidad y por los recursos de los 
hacendados" (García Treviño, 1956, p. 51). Además, para que no quepan dudas de que el ejido y las tierras comunales están sujetos a un régimen que los diferencia de la propiedad privada, Andrés Molina Enníquez, el padre de la reforma agraria mexicana, comentó años más tarde que "los distinguidos miembros de la Asamblea Constituyente de Querétaro tenían presente que tanto las comunidades como los trabajadores del campo estaban en condiciones de tal inferioridad ante los terratenientes y los empresarios industriales, respectivamente, que el gobierno no podía dejar de defender sus intereses para lograr un equilibrio de fuerzas y velar por una justicia cabal, desempeñando en ambos casos la función que corresponde a un fiscal o fiscal general en todos los conflictos que involucren a menores ". Esto da origen a una relación de "tutela" entre el Estado y los campesinos, considerados incapaces como niños o menores de edad desde el punto de vista jurídico.

Sin cuestionar el principio que sirve de fundamento a las disposiciones constitucionales relativas a la tutela que ejerce el Estado sobre los campesinos, la escuela cardenista de pensamiento introdujo dos cambios importantes en la política gubernamental: la concepción de la reforma agraria como instrumento de estabilidad social y la creación del ejido como institución permanente. La aplicación de esta política se basó en dos hipótesis: no se podía seguir postergando la demanda fundamental del movimiento campesino -el acceso a la tierra - so pena de que el movimiento de masas desbordara el marco constitucional, ${ }^{6}$ y el ejido debía convertirse en el eje de la política rural del gobierno. ${ }^{7}$

El ejido, que hasta entonces se había considerado como un instrumento para contener las reivindicaciones campesinas, adquirió nuevas características (que mantendría hasta 1991$)^{8}$ a consecuencia de una vinculación doble: entre el ejido y el Estado, específicamente los organismos gubernamentales, y entre el ejido y los ejidatarios, que actúan como socios en esa unidad productiva.

En el gobierno de Cárdenas el ejido debía desempeñar dos funciones económicas: el abasto de alimen-

\footnotetext{
${ }^{5}$ Citado en Córdova (1974, pp. 339-340).

${ }^{6}$ De hecho, muchas asociaciones regionales de campesinos acusaban a la nueva élite gobernante de traicionar los ideales más importantes de la revolución mexicana.

7 Castillo (1956, pp. 5-164) ofrece una original interpretación del problema del ejido en México.

${ }^{8}$ La reforma constitucional del artículo 27 y la nueva ley agraria fueron aprobadas por el Congreso y promulgadas entre noviembre de 1991 y febrero de 1992, en el gobierno del Presidente Salinas,
}

tos y materias primas a bajo costo, y el impulso al mercado interno gracias a la demanda generada por los propios campesinos dueños de la tierra. Sin embargo, para los cardenistas, el ejido sólo podía cumplir esas funciones económicas satisfactoriamente si se vinculaba con organismos gubernamentales. Por lo tanto, se estableció una pirámide orgánica de base amplia y numerosos niveles, que vinculaba la dirección del ejido (los comités ejecutivos y el Consejo Supervisor) ${ }^{9}$ con las ligas agrarias, y a través de éstas con la Confederación Nacional Campesina (CNC).

Aunque la última etapa de este proceso de organización culminó con la promulgación de un decreto presidencial en virtud del cual se creaba la Confederación Nacional Campesina, a la que estaban obligados a pertenecer todos los miembros de los ejidos, sería un error atribuir su constitución exclusivamente a una decisión del gobierno. Antes de que se creara la Confederación, hubo un largo período de protestas campesinas e intentos de establecer organizaciones regionales, que en muchos casos condujeron a la formación de las ligas agrarias estatales y los organismos suprarregionales de campesinos, como la Liga Nacional Campesina, encabezada por Ursulo Galván, del estado de Veracruz, a comienzos de los años treinta. Por consiguiente, la presión de las bases provocada por las protestas campesinas se sumó a la decisión del gobierno central de consolidar su hegemonía en el sector rural, para crear la CNC.

La CNC no puso fin a la tutela estatal sobre los campesinos. Por el contrario, ésta formaba parte de un conjunto de instituciones, creadas o reforzadas durante el gobierno de Cárdenas, con la expresa intención de facilitar el desarrollo del ejido y asegurar la hegemonía estatal. Las reformas de la ley agraria realizadas en 1934 y 1935 otorgaron al Departamento de Asuntos Agrarios y Colonización numerosas facultades discrecionales para proteger y supervisar el desarrollo de ejidos y comunidades y, sobre todo, para reglamentar la adquisición de tierras. La constitución de ejidos colectivos en zonas de riego que habían sido expropiadas a latifundistas dio origen a una serie de organismos gubernamentales de desarrollo rural, siendo el más importante el Banco Nacional de Crédito Ejidal. Aunque se solía considerar que estas instituciones habían sido creadas para apoyar y atender a los ejidos hasta que se sostuvieran por sí solos, tanto en la práctica como en el criterio e intención de los direc-

\footnotetext{
9 En Gordillo (1998 b) se analizan estos temas en detalle.
} 
tores políticos de estos órganos, su objetivo era perpetuar la intervención gubernamental en la producción, la regulación y el abasto de productos agrícolas, sobre todo de alimentos básicos.

No tardó en producirse una primera "división del trabajo" entre todas estas instituciones vinculadas con el medio rural: la CNC se encargó de encauzar las demandas de los campesinos, sobre todo en materia de asignación de tierras; los organismos gubernamentales eran responsables de cumplir y regular esas reivindicaciones, sobre todo las relacionadas con la organización de la producción ejidal.

Como se ha dicho, las políticas que a la postre se plasmaron en la ley agraria mexicana compartían dos conceptos: que el Estado debe proteger los intereses de los campesinos como una forma de velar por el equilibrio social, y que esta protección o tutela debe ser temporal.

La solución al problema del medio rural como "menor de edad" jurídico, que se impuso a fines de los años cuarenta en México, cuando se institucionalizó la revolución mexicana, se basa en una fórmula híbrida, enunciada por primera vez en el proyecto de ley presentado por el Presidente Calles en 1925 y cuyo más claro exponente fue un ex integrante del ejército zapatista. La fórmula podría resumirse como una combinación de derecho de propiedad en común con disfrute prívado. ${ }^{10} \mathrm{El}$ zapatista Soto y Gama argumentaba lo siguiente: "La propiedad pertenece en común a la colectividad, ¿por qué?, porque la colectividad tiene derecho de imponer modalidades a esa propiedad, mejor dicho a ese usufructo, por esto el disfrute es privado, porque el lote se da para que se disfrute en todos sus productos, en toda la cosecha por la persona que lo recibe; pero esta última ¿tiene la propiedad privada de derecho romano, la propiedad típica del capitalista? evidentemente que no (...) no tiene, pues, el tercero de los derechos característicos de la noción íntegra de la propiedad (...) recibe pues la tierra como una función social, no tiene el derecho de abusar. Y el abuso peor que se puede hacer de la tierra es no trabajarla". (Córdova, 1974, pp. 339-340).

El ideal de la corriente moderada, según la cual el objetivo fundamental del ejido era el desarrollo de la propiedad privada, condujo a la subdivisión de algunas tierras ejidales en parcelas, cuya superficie originalmente no debía superar las 20 has. El legado de la escuela radical fue el importante papel atribuido a

10 Esta expresión proviene de Córdova (1974, p. 339). las tradiciones comunitarias, con la designación de un área comunal dentro de cada ejido. En los treinta años siguientes se impuso una estrategia moderada por la cual la reforma agraria y el sistema ejidal se consideraban en esencia como un mecanismo político para asegurar la estabilidad en el medio campesino. Se subestimó por completo el papel del ejido como unidad productora, asignándose la función del abasto de alimentos a la agricultura comercial privada.

Sin embargo, esta fórmula híbrida encerraba dos contradicciones, que entraban en pugna constantemente, lo que, en gran medida, creó el caldo de cultivo para la agitación campesina de hoy. La primera se relaciona con el derecho a la propiedad, y podría describirse en los siguientes términos: el derecho al usufructo privado de la propiedad puede conducir $-\mathrm{y}$ de hecho conduce- a un creciente debilitamiento de la propiedad colectiva, en la medida en que da mayor acceso a los recursos económicos y políticos a algunos ejidatarios, lo que permite la acumulación de capital privado. Pero el derecho a la propiedad colectiva puede traducirse - y de hecho se ha traducido- en la prohibición del usufructo privado, debido a una inercia social que impide el aprovechamiento del potencial productivo de la tierra comunal. ${ }^{11}$

La segunda contradicción se plantea entre el derecho a la propiedad y el derecho de los agricultores a organizarse (Castillo, 1956). En último término el dominio de la tierra queda en manos del Estado en su calidad de representante de la nación, pero por tratarse de un sistema presidencial el derecho recae en la presidencia. Esta situación agudiza la existencia de un abanico de organismos gubernamentales que intervienen en el ciclo productivo del ejido. En la medida que éstos han debilitado al ejido como cuerpo representativo, se ha cercenado la capacidad de organización de las comunidades para defender sus propios intereses.

Estas dos contradicciones afectaron el funcionamiento interno del ejido y, sobre todo, lo que podría definirse como su "sistema poliárquico". Desde un comienzo se establecieron dos órganos rectores colegiados: un Comité Ejecutivo Ejidal —integrado por un presidente, un secretario, un tesorero y tres vocalesy un Consejo Supervisor, también integrado por seis miembros; además, existía una Asamblea General del Ejido, que se reunía por lo menos una vez al mes, para definir las políticas generales del ejido y solucionar

\footnotetext{
11 Esta contradicción merece particular atención, ya que el $67 \%$ de la tierra asignada a los ejidos es de propiedad colectiva. Véase de Janvry, Gordillo y Sadoulet (1997).
} 
conflictos internos. Se aplicó el principio democrático de representación minoritaria y mayoritaria y, hasta la reforma jurídica de 1983, el Consejo Supervisor quedaba automáticamente integrado por los candidatos que sacaban la segunda mayoría en la elección del Comité Ejecutivo Ejidal. El sufragio era directo y universal, basado en una lista de ejidatarios con plenos derechos - el registro de votación- y la votación era directa, secreta y personal. Asimismo, se adoptaron reglamentos que establecían los métodos de la toma de decisiones, ejecución de las mismas, aplicación de sanciones, distribución de utilidades, etc. Los vocales podían presentarse a la reelección, pero en el segundo período debían obtener el $75 \%$ de los votos de los ejidatarios.

Sin embargo, todos los derechos y facultades que permitían organizarse libremente a los ejidatarios, y que hacían del ejido un órgano de representación directa de los campesinos, fueron severamente distorsionados por efecto de las dos contradicciones implícitas en la fórmula híbrida que se impuso finalmente.

En otros términos, se podría decir que, como órgano representativo de los campesinos, el ejido no podía dejar de estar en conflicto permanente con el ejido en su calidad de aparato estatal. Esta inevitable tensión se reflejó en las modalidades de elección, que determinaban en qué forma se expresarían los conflictos y las luchas en el campo. ${ }^{12}$ Como resultado de esas luchas, se reforzó la función del ejido tanto como órgano representativo de los campesinos cuanto como aparato estatal, y ninguno de esos aspectos desapareció del todo hasta la enmienda del artículo 27 de la Constitución de 1991.

\section{II}

\section{Las lealtades y los beneficiarios a título gratuito (1940-1970)}

Después de Cárdenas, surgió un modelo de desarrollo que propugnaba un rápido proceso de industrialización para aprovechar la coyuntura después de la segunda guerra mundial. El conflicto típico de las élites de otros países latinoamericanos que derrotaron los intentos de reforma agraria, entre las burguesías agrarias y agroexportadoras, por una parte, y las nacientes burguesías industriales por la otra, no apareció en México sino cuando el proceso de reforma agraria estaba casi concluido. Por lo tanto, la estrategia de "modernización sin expropiación", ${ }^{13}$ que tuvo tanto éxito en los años sesenta y setenta en los demás países latinoamericanos, asumió una forma algo diferente en México en los años cuarenta. En el pacto político concertado entre las élites dominantes en el segundo quinquenio de los años cuarenta, se encomendó principalmente a la agricultura privada el abasto de alimentos a los centros urbanos, cuyo crecimiento a todas luces se veía acicateado por el incipiente proceso de industrialización. Sin embar-

\footnotetext{
12 Véase Prseworski (1985, especialmente la p. 73): "La afirmación de que las relaciones sociales determinan los conflictos de clase no debe interpretarse mecánicamente. Las relaciones sociales ... son una estructura de opciones que se da en un punto específico de la historia".

13 Véase de Janvry y Sadoulet (1989).
}

go, la agricultura ejidal, es decir el sector reformado, seguía en pie, por precaria que fuera su existencia en los años siguientes. Con estos supuestos — sobre todo el del carácter irreversible de la reforma agraria, pese a que en la práctica estuviera bloqueada desde entonces- la estrategia de "modernización sin expropiación" resultó tan eficaz como en otros países, dado que indujo al Estado a reasignar los fondos destinados a la reforma agraria y a reorientar a los organismos respectivos a la modernización de las explotaciones agrícolas medianas y grandes (de Janvry y Sadoulet, 1989, p. 1406).

\section{Supervivencia y transformación}

Quizás uno de los aspectos más interesantes que se plantea al analizar este período sea el de la supervivencia misma del ejido. ¿Por qué si el ejido se había convertido en una reserva barata de mano de obra y era explotado y descapitalizado sistemáticamente, sin beneficiar de ninguna manera a sus miembros, no se levantaban los propios ejidatarios en contra de la institución? Y si el gobierno fomentaba la aplicación de distintos métodos para desintegrar al ejido y para colocar en el sitial de honor a la agricultura privada, ¿por qué no acabó su tarea? 
Pragmáticamente, podría contestarse la segunda pregunta alegando que el Estado no destruyó al ejido por completo porque funcionaba muy bien, en la coyuntura reinante, para fines tanto de acumulación de capital en el medio rural, como para el control político. Pero esta es una explicación a posteriori de un fenómeno anterior. A menos que el Estado se considere un ente de una racionalidad absoluta, en esta respuesta no se toman en cuenta las razones que aconsejaron al gobierno poner fin al período de transición que suponía el establecimiento del ejido, a pesar del constante rechazo de las políticas populistas por los estamentos superiores del gobierno desde fines de los años cuarenta hasta $1970 .^{14}$

En cuanto a por qué los ejidatarios no rechazaron el sistema, la respuesta podría hallarse en barreras institucionales que impedían modificar el sistema jurídico sin perder el acceso a la tierra. Sin embargo, la decisión de los ejidatarios de no abandonarlo, debe acotarse según el significado que se le dé al término "abandonar". También entra en juego otro elemento clave al que se refiere Hirschman (1977, pp. 78-104): la lealtad (presente y pasada), como mecanismo que fortalece la adhesión a una colectividad en determinadas circunstancias.

El "abandono" del ejido habría supuesto, en términos estrictos, la pérdida de la parcela ejidal y, en términos más amplios, la pérdida de la calidad de ejidatario. En el período considerado, esta opción habría ofrecido diversas ventajas, como la posibilidad de ganar un mejor salario en otras regiones agrícolas más dinámicas, en las ciudades o en las zonas de emigración a los Estados Unidos. Además, el auge y la consolidación del cacicazgo en muchas zonas rurales de México crearon en esa época condiciones de coexistencia tan intolerables como para compensar por la incertidumbre de trasladarse a otra zona rural o a ciudades grandes. Hubo casos de abandono: tanto en los polos agrarios más dinámicos como en los grandes centros urbanos hay fuertes indicios de las corrientes migratorias desde los ejidos en esos años. ${ }^{15}$ Sin embargo, esta migración, cuando llegaba a ser permanente, suponía el traslado de parte de la unidad familiar, pero no incluía al ejidatario mismo, es decir el miembro de

\footnotetext{
${ }^{14}$ En Torres y Medina (1978, 1979a y 1979b) passim. se presenta un estudio muy bien documentado de la oposición a las políticas populistas.

15 Paré (1977) describe principalmente las migraciones de una zona rural a otra. Astorga (1985) y Arispe Schloesser (1985) presentan interesantes interpretaciones de las migraciones rurales.
}

la familia titular de los derechos agrarios; cuando lo incluía, éste había negociado previamente un acuerdo con las autoridades del ejido, para alquilar o prestar su parcela sin perder sus derechos de dominio. En todo caso, la migración no suponía un rompimiento con el ejido, lo que se podía atribuir a que la primera generación de ejidatarios estaba en una situación similar a la descrita por Hirschman: alto costo de ingreso a la organización, lealtad absoluta y barreras institucionales que dificultaban su abandono (Hirschman, 1977). El alto costo del ingreso se debe a que, generalmente, los ejidatarios habían luchado durante muchos años, con ingentes sacrificios, incluso con peligro de su vida, para conseguir la tierra. La lealtad que mostraban al ejido, al que reconocían como la entidad que naturalmente los representaba, tenía fuertes raíces históricas, ya que el ejido surgió de múltiples luchas y la operación misma de la institución estaba muy marcada por la movilización campesina.

Como es evidente, las barreras institucionales no limitan la posibilidad de renunciar al ejido sino de hacerlo y, a la vez, conservar la propiedad de la parcela y, en cierta medida, el carácter de ejidatario. Es significativo que en plena ofensiva en su contra en el decenio de 1940, el desmantelamiento de los ejidos puso fin a las modalidades de explotación colectiva de la tierra, pero no al ejido en sí mismo. En resumen, la posesión de parcelas ejidales y el pertenecer a un ejido eran una forma de seguridad para los ejidatarios.

Entra aquí otro elemento: tanto la lealtad como las barreras institucionales impiden que el ejidatario abandone el ejido o alce la voz para protestar contra sus dirigentes. Se produjo entonces una especie de protes-. ta sorda, que se expresó en la emigración y en el ausentismo de las asambleas del ejido. Como comentario al margen, cabe señalar que los mayores conflictos sociales de ese período se dieron en las zonas rurales en que se estaba desmantelando la agricultura colectiva.

Esta interpretación nos lleva a dar una respuesta preliminar a la segunda pregunta planteada. Desde el punto de vista de la élite política de esa época, que propugnaba la industrialización, era evidente que el apoyo que recibiría el proceso desde el sector agrícola debía provenir de la agricultura privada. Así lo demuestra el hecho de que casi todas las políticas estatales estuvieran destinadas a fomentarla. Sin embargo, el desarrollo de un marco institucional en el cual apoyar esa transformación de la política agraria a favor del sector privado demoraría algún tiempo, porque en lo inmediato, los organismos gubernamentales estaban muy comprometidos en apoyar al ejido (o en preten- 
der ayudarlo), y el cambio de política despertaba resistencia y provocaba conflictos en la burocracia de esas instituciones. ${ }^{16}$

Además, el sector empresarial no respondió automáticamente a los estímulos estatales, sobre todo debido al trauma provocado por las expropiaciones durante la presidencia de Cárdenas, y el ejido seguía desempeñando una importante función productiva, especialmente de alimentos básicos. Por último, era evidente para todos que la reforma agraria le había permitido al. Estado evitar los conflictos en el medio rural por muchos años. A eso hay que sumar que el surgimiento de los caciques, la desintegración interna de los ejidos y la posición marginal a la que había quedado relegado el ejido en las políticas públicas impidieron que se produjeran trastornos sociales y que se siguieran adoptando medidas para poner fin al ejido. En cierto sentido, el mantenimiento del statu quo se debió a los buenos resultados registrados en todo el sector agrícola. ${ }^{7}$

Resumiendo este aspecto relevante: el ejido no fue privatizado porque, para los campesinos, representaba un dispositivo fundamental de seguridad, que facilitaba el cumplimiento de múltiples propósitos, en tanto que para el gobierno representaba un aparato político esencial para asegurar la estabilidad en el campo y permitir que la agricultura comercial privada siguiera encargándose del abasto de alimentos.

\section{La movilización social en demanda de tierras}

A fines del decenio de 1960, varios hechos se concatenaron para modificar la situación descrita, y en gran medida moldearon las tendencias en que ocurriría la nueva ola de movilizaciones campesinas.

A medida que la agricultura privada comercial se concentraba en cultivos lucrativos tanto de exportación como de insumos para los complejos agroalimentarios, con el consiguiente abandono del cultivo de cereales,

\footnotetext{
${ }^{16}$ Un ejemplo típico de esta situación es el conflicto surgido entre la Oficina de Estudios Especiales de la Secretaría de Agricultura, auspiciada por la Rockefeller Foundation, y el Instituto de Investigaciones Agropecuarias, dependiente de la misma Secretaría, pero influenciado por la Liga de Agrónomos Socialistas en lo que respecta a la orientación que debía darse a los estudios agrícolas en México.

17 De comienzos de los años cuarenta a mediados del los sesenta, la producción agropecuaria tuvo una evolución muy dinámica. Entre 1946-1948 y 1964-1966, el producto agropecuario aumentó en $7.1 \%$ anual, que se tradujo en un crecimiento anual per cápita de $3.8 \%$, dado que el crecimiento de la población era de $3.2 \%$. Véase Gordillo (1990).
}

se imponía con urgencia la necesidad de reorientar el sistema de ejidos hacia la producción de alimentos básicos y de otorgar más importancia a su función de unidad productiva que, como ya se ha dicho, había quedado relegada a un segundo plano desde los años cuarenta. No cabe duda de que este cambio en el régimen de cultivos obedecía a una alteración de la división internacional del trabajo y a la presencia de las empresas transnacionales productoras de alimentos a fines de los años cincuenta, pero también fue fomentado por la política general del gobierno, que necesitaba divisas para financiar el proceso de sustitución de importaciones.

Aparecieron también otros fenómenos, inherentes al tipo de desarrollo rural que estos cambios estaban gestando. La raíz de esos cambios debe buscarse en la época en que los incentivos estatales para la producción de alimentos básicos daban preferencia a la agricultura comercial privada, de gran rentabilidad, basada en el incremento del volumen físico de la producción gracias a un mayor rendimiento de los cultivos y a la extensión de la superficie cultivada. Este proceso se veía bloqueado por dos factores: el capital necesario para mantener el mayor rendimiento (sobre todo de alimentos básicos) o para continuar las obras de riego en gran escala, y el resurgimiento de los movimientos campesinos que ejercían abierta presión para impedir el acaparamiento ilícito de tierra, método favorito de ampliar la superficie de cultivo controlada por la agricultura privada.

A partir de 1965 se notaban síntomas crecientes de crisis en el sector agrario, siendo los más evidentes la reducción de la tierra cultivada y el menor ritmo de crecimiento de la producción de maíz en tierras de secano. La combinación de ambos indicadores muestra que la crisis afectaba sobre todo al sistema de ejidos. ${ }^{18}$ La crisis se debía tanto a la descapitalización desenfrenada de la agricultura ejidal como a las dificultades que enfrentaban los migrantes internos en busca de trabajo, por efecto de la transición a una nueva etapa en el proceso de sustitución de importaciones de que dependía el desarrollo agropecuario, y la creciente mecanización de la agricultura comercial. El ejido se veía afectado en realidad por una doble crisis: de producción económica y de reproducción social.

La agricultura comercial abandonó paulatinamente la producción de cereales, y se dedicó fundamentalmente a los forrajes y a los cultivos del complejo soya-

\footnotetext{
18 Véanse los datos estadísticos presentados en el artículo de Gómez Olivier (1978, pp. 714-727).
} 
sorgo, a lo que se sumó el desarrollo de la ganadería que ocupaba grandes extensiones destinadas anteriormente a los cereales. Debido a su descapitalización, el ejido no pudo aprovechar ese vacío; además, del 35\% al $45 \%$ de las unidades ejidales no podía obtener ni la mitad de su ingreso de la agricultura, y les era cada vez más difícil encontrar otras fuentes de ingresos. A la imposibilidad del ejido de acumular ahorros propios se sumaron las crecientes dificultades de las unidades familiares para crear su propio fondo de consumo. La agricultura ejidal respondió a esta coyuntura dando mayor importancia al autoconsumo, reduciendo el área de cultivo, lo cual, como se mencionó, desembocó en la crisis agraria de fines del decenio de 1960.

Estas mismas circunstancias dieron origen a otro fenómeno, aparentemente paradójico: ante la mayor presión ejercida sobre la agricultura ejidal, y a pesar de la difícil situación en los mercados de trabajo externos, se produjo una corriente migratoria ininterrumpida, causante, en gran medida, del crecimiento explosivo de los cinturones de pobreza en torno a las grandes ciudades, y del surgimiento de pueblos de campesinos en las cercanías de las áreas de explotación agrícola comercial y de ghettos campesinos en las ciudades y los pueblos grandes (es decir, barrios habitados por personas procedentes de la misma zona campesina, que no sólo mantienen sus vínculos culturales y afectivos con sus comunidades de origen, sino que establecen una corriente constante de ayuda económica). Sin embargo, igual que en el período anterior, estas corrientes migratorias que habían llegado a ser permanentes, presuponían el mantenimiento del vínculo legal con el ejido y no su rompimiento.

Otro fenómeno comenzaba a descollar: el traspaso generacional de los ejidatarios, pues no hay que olvidar que la mayoría de los miembros originales de los ejidos recibieron sus tierras entre 1930 y 1940. Aunque la distribución de tierras no se interrumpió, y de hecho cobró nuevo ímpetu entre 1964 y $1970,{ }^{19}$ este

\footnotetext{
${ }^{19}$ Según las cifras oficiales, durante la presidencia de Díaz Ordaz se distribuyeron 24 millones de hectáreas, es decir 16 más que durante la presidencia de Cárdenas. Las características de esta distribución quedan en evidencia cuando se compara el número de miembros de los ejidos beneficiados en ambos períodos; en la presidencia de Díaz Ordaz, las tierras distribuidas beneficiaron a alrededor de 300000 unidades familiares, mientras que en la presidencia de Cárdenas beneficiaron a poco más de 750 000. En el período comprendido entre 1964 y 1970, se consideran también las tierras distribuidas en otros períodos, pero efectivamente entregadas en esos años. Asimismo, se adoptaron nuevas disposiciones legales, en vir-
}

traspaso generacional fue muy importante, por el número de ejidatarios y la situación geopolítica de los ejidos.

La forma que asumió ese traspaso fue muy distinta a la de las primeras generaciones de ejidatarios; quizá lo más importante fue que en esta etapa se combinaron: i) un proceso de fragmentación de la parcela ejidal, que dio acceso a la tierra al hijo mayor, aunque en forma inestable; ii) la constitución de comités de solicitantes de tierras - integrados fundamentalmente por los otros hijos del ejidatario y por vecinos-que pedían a las autoridades la expansión del ejido original, y iii) la emigración permanente y temporal de los hermanos menores, en un proceso en que primero se trasladaba una parte de la unidad familiar a una zona receptora, se instalaba allí, y creaba una base para recibir después a los demás miembros de la unidad familiar, en calidad de emigrantes temporales.

Los años sesenta se caracterizaron por una gran inestabilidad de los hogares campesinos, no sólo a consecuencia de la emigración, sino también de numerosos conflictos, dentro de la unidad familiar, entre unidades, contra los caciques ejidales, etc., todos los cuales giraban en torno al acceso a una parcela.

Dentro del ejido había cada vez más partidarios de su transformación, lo que se traducía en la oposición directa a los dirigentes y en un proceso lento, a veces clandestino, generado por la constitución de comités solicitantes de tierra formados por los hijos de los ejidatarios y los vecinos asentados en el ejido. De una u otra manera, la creación de estos comités que reclamaban tierras generó nuevas formas de pensar, relacionadas directamente con la operación de los ejidos, y activó la memoria histórica de los ejidatarios originales. Además, los ejidatarios se dieron cuenta de que tenían mucho más influencia sobre la acción del gobierno en reacción a sus movilizaciones, aunque se limitaran en general al ejido, y también al boicot, que en este caso consistía en dejar ociosa la tierra (Hirschman, 1977, pp. 86-87).

Todos estos procesos condujeron a un nuevo momento de protesta campesina, que se inició en los años setenta y continúa hasta hoy.

tud de las cuales la entrega de la tierra se definía como la asignación de un terreno ubicado a gran distancia del lugar de residencia original de los beneficiarios ("nuevos centros de población"). La verdadera intención de estas medidas era mitigar la presión ejercida sobre las grandes haciendas regadas, pero en la práctica impidió en muchos casos el traslado de los campesinos a otras zonas. Sin embargo, las tierras fueron consignadas como distribuidas. 


\section{III}

\section{La dinámica del control político (1970-1988)}

La respuesta del gobierno a esta crisis fue típica de los ciclos políticos mexicanos. Durante treinta años después del régimen de Cárdenas, las políticas que él había aplicado en el campo o se repudiaban por ser populistas o se las consideraba anticuadas, aplicables a un período ya superado. Pero ahora nos encontramos con el recientemente electo gobierno de Luis Echeverría, quien tras la sangrienta represión del movimiento estudiantil en 1968, tenía que encontrar una nueva fuente de legitimación y que además se veía enfrentado a una nueva marejada de movilizaciones campesinas como no se había visto desde el decenio de 1930. Ante las nuevas demandas de tierras de los miembros de los ejidos y las señales incipientes, pero claras, de un estancamiento de la actividad agropecuaria, el régimen recurrió al arsenal de políticas y medidas cardenistas, con la evidente intención de dar nueva vida al contrato social, de crucial importancia en los años cuarenta.

Para lograr ese objetivo, el régimen de Echeverría introdujo dos reformas importantes. Siguiendo el ejemplo de la escuela cardenista, adoptó al ejido como centro de la intervención estatal y principal unidad productora, que debía garantizar el abasto de alimentos y la autosuficiencia. La ley agraria, que no había sufrido enmiendas importantes desde 1946, se reformó por completo, añadiéndosele un capítulo dedicado a las "actividades económicas del ejido". Paralelamente, se crearon diversas instituciones y se amplió el mandato de las instituciones ya existentes, a fin de que pudieran aplicar las nuevas disposiciones legales. Hasta entonces, ningún gobierno, ni siquiera el de Cárdenas, había recibido facultades tan amplias como las que supusieron las reformas realizadas en el gobierno de Echeverría. En la década de 1970 se creó la Secretaría de Reforma Agraria, y se unieron las de agricultura y recursos hidráulicos en una sola entidad con grandes atribuciones. También mediante fusión de organismos se crearon instituciones paraestatales para la provisión de servicios de crédito rural, distribución de alimentos, desarrollo agroindustrial y producción y distribución de insumos, entre otros, que dieron mucho mayor alcance a la acción estatal.

En segundo lugar, el gobierno adoptó medidas para hacer frente a la movilización campesina - encabezada fundamentalmente por grupos de base popular que cuestionaban el papel predominante de las organiza- ciones oficiales de campesinos- tratando de impartir nueva vitalidad al sistema corporativo. Aunque durante el primer año del nuevo régimen se recurrió al ejército para combatir con dureza las nuevas ocupaciones ilegales de tierras, las extensas movilizaciones obligaron poco después al gobierno a recurrir a sus facultades discrecionales, a fin de confiscar tierras privadas y distribuirlas entre los campesinos sin tierras. De hecho, durante el gobierno de Echeverría se expropiaron extensas áreas en los distritos de riego, donde se encontraban las mejores tierras, y la superficie distribuida alcanzó uno de los niveles más altos registrados desde el período cardenista. Esto provocó una profunda crisis política, ya que tanto las organizaciones de campesinos como los agricultores privados quedaron descontentos con las medidas del gobierno.

Es probable que el fenómeno más destacado de este período sea el grado de perfeccionamiento y extensión del control político al sector reformado. Luego de haber analizado el ejido desde el punto de vista histórico - que por razones obvias se limita al siglo $\mathrm{XX}$ - examinaremos la interacción entre sus componentes, en el supuesto de que el motor primario de su evolución es la función que cumple como instrumento de control político. Cabe recordar que la transformación del ejido en instrumento de control político por parte del Estado fue un proceso lento, que no se dio en forma pareja en todo el país. Los ejidos siempre han sido muy heterogéneos. No sólo se diferencian en cuanto a su dotación de recursos naturales, sino también a la composición de sus miembros y a la trayectoria de su lucha por la tierra. A pesar de estas diferencias, es posible analizar el modelo de control político aplicado en todos los ejidos. El modelo operaba simultáneamente aunque con distinta intensidad según la región y la época, en tres planos: el marco jurídico, la representación política y la reproducción social. A pesar de que las organizaciones gubernamentales y las intervenciones estatales adoptaron distintas formas, todas se basaban en un modelo de control autoritario y jerárquico, pero a la vez incluyente.

\section{La intervención estatal en los ejidos}

Existían códigos legales que regulaban muy estrictamente el funcionamiento interno de los ejidos y esti- 
pulaban los derechos y los deberes de los ejidatarios. Por ejemplo, éstos tenían que trabajar la tierra personalmente, no pudiendo contratar jornaleros. No podían alquilar la tierra ni venderla. Si el ejidatarío se ausentaba del ejido por más de dos años, perdía el derecho a la tierra. Todos los ejidatarios tenían que designar por escrito a los herederos de la tierra, por orden de sucesión; en la mayoría de los casos, se designaba al cónyuge o a un colaborador como sucesor preferido. Los ejidatarios tenían derecho a voto en las elecciones del comité ejecutivo de la asamblea y a ser elegidos como miembros de éste. También tenían derecho a voto para la aprobación del reglamento interno en el que se estipulaban sus derechos, sobre todo con respecto a las tierras comunales. Cada ejidatario tenía derecho también a un lote urbano para establecer su residencia, y a un máximo de 20 ha para cultivos directos.

Había cuatro modalidades de acceso a la tierra. En el caso de una comunidad indígena documentada, el acceso derivaba del derecho a restitución. Si el interesado vivía en un asentamiento en que había tierra para distribuir dentro de un radio determinado, podía recibir tierras mediante dotación. Si el interesado estaba dispuesto a trasladarse a otra región o estado, podía recibir tierras en zonas destinadas a la colonización, en las que se crearían nuevos centros de población. Por último, un ejido podía obtener nuevas tierras e incorporar a nuevos ejidatarios. ${ }^{20} \mathrm{En}$ el decenio que precedió a las últimas reformas, el gobierno autorizó la incorporación de unidades familiares cuyos miembros tenían título de ejidatarios, pero no tenían tierras (ejidatarios con derechos a salvo).

Existían variados mecanismos que permitían al Estado intervenir en los asuntos internos de los ejidos para hacer cumplir las leyes (Whetten, 1948; Fernández y Fernández, 1973).

i) El Estado intervenía con el objeto de legalizar el proceso interno de toma de decisiones. Por ejemplo, en la asamblea del ejido se aprobaban casi todas las decisiones importantes: distribución de terrenos urbanos y de parcelas de cultivo; aprobación de reglamento interno, solicitudes de crédito y otro tipo de servicios públicos como escuelas, sistemas de agua potable y caminos; reglamentación del acceso a las tierras de uso colectivo y la definición de las modalidades de trabajo. Sin embargo, para validar las decisiones de una asamblea, debía estar presente en ella un representan-

\footnotetext{
${ }^{20}$ Los nombres jurídicos de estas formas de adquisición son: restitución, dotación (creación de) nuevos centros de población y ampliación.
}

te de la Secretaría de Reforma Agraria, sucesora del Departamento Agrario. Además, la convocatoria a una asamblea sólo se consideraba legal con el aval de un representante de la Secretaría de Reforma Agraria o del alcalde. Las asambleas extraordinarias sólo podían ser convocadas por la Secretaría.

ii) El Estado intervenía en casos de arbitraje. Por ejemplo, las controversias familiares sobre uso de las parcelas o los conflictos sobre herencia tenían que someterse a los tribunales administrativos estatales, que formaban parte de la Secretaría de Reforma Agraria y también dictaminaban en casos de disputas por cuestiones de límites entre los ejidos, entre ejidos y hacendados, y entre ejidos y comunidades indígenas.

iii) El Estado controlaba la asignación de recursos públicos al ejido. Desde fines del decenio de 1970, los bancos comerciales otorgan préstamos a los ejidatarios, pero hasta entonces sólo los bancos estatales ofrecían ese servicio. Para que un ejidatario obtuviera un crédito, debía tener una autorización oficial de la asamblea, pero el crédito se extendía a nombre del ejido. Por lo tanto, todos los ejidatarios eran codeudores del total del crédito y tenían que ofrecer su cosecha como garantía. Para que ésta sirviera de garantía, el banco oficial firmaba un contrato con el ejido, con cada ejitadario receptor de un crédito y con la organización estatal que comercializaba la cosecha y los productos ganaderos del ejido. Esta organización, la Compañía Nacional de Subsistencias Populares (CONASUPO), compraba las cosechas a un precio garantizado y emitía cheques a nombre del ejidatario y del banco oficial. Parte del crédito se pagaba en especie. Si se había destinado a la compra de fertilizantes, Fertilizantes Mexicanos (FERMITEX), la institución paraestatal encargada de la producción y distribución de fertilizantes, se responsabilizaba del reembolso. Si había sido destinado a insecticidas, otros productos químicos o maquinaria, el banco firmaba contratos con las empresas privadas pertinentes. En los distritos de riego, también se exigía un permiso de riego, que otorgaba la Secretaría de Agricultura y Recursos Hidráulicos (SARH), anteriormente denominada Secretaría de Recursos Hídricos y, en una etapa anterior, Comisión Nacional de Agua (CNC) (Gordillo, 1988 b).

Hasta hace muy poco tiempo, para obtener un préstamo del banco oficial los ejidatarios debían sacar un seguro de cosecha en una institución oficial. También había empresas estatales que prestaban servicios relacionados con toda la cadena de comercialización de café, cacao, caña de azúcar, frutas tropicales y otros cultivos especiales. Estas empresas paraestatales otor- 
gabán créditos, compraban la cosecha, proporcionaban insumos y prestaban asistencia técnica. La asamblea del ejido tenía que autorizar en cada caso la participación del ejido en estas operaciones. Abrumada por las numerosas exigencias del Estado, la asamblea del ejido tenía que limitarse a deliberar sobre políticas ya aprobadas por el gobierno, con lo cual se sofocaban las iniciativas que podían haber nacido de los propios ejidatarios.

iv) El Estado intervenía en múltiples servicios de bienestar social e infraestructura. La Secretaría de Educación Pública (SEP) tenía a su cargo la creación de escuelas y la contratación de maestros y había organizaciones que se ocupaban de la salud, la vivienda, la ayuda alimentaria, las redes viales, los asuntos indígenas y las actividades de esparcimiento. La extensa intervención estatal en los servicios sociales se centraba en las comunidades indígenas y en los ejidos más pobres, lo que contribuyó a la distribución funcional de organismos estatales entre ejidos y acentuó la heterogeneidad del sector rural; mientras los organismos estatales de desarrollo social se ocupaban fundamentalmente de atender las necesidades de los ejidos pobres y las comunidades indígenas, los que fomentaban la producción se dedicaban a los productores privados y los ejidos más prósperos.

\section{La representación política}

En un segundo plano, el modelo de control político operaba a través de distintas formas de representación política en el ejido. La política intervenía en todo. Hasta mediados de los años ochenta, con muy pocas excepciones en las décadas de 1950 y $1960,{ }^{21}$ para recibir bienes y servicios públicos los ejidatarios tenían que pertenecer a la Confederación Nacional Campesina, que a su vez estaba afiliada al Partido Revolucionario Institucional (PRI), el partido gobernante. Por lo tanto, ya fuera en virtud de una decisión de la asamblea del ejido o, más común aún, de una decisión de su comité ejecutivo, los ejidatarios pasaban a ser miem-

\footnotetext{
21 En esos años se produjeron dos importantes divisiones del férreo monopolio político de la Confederación Nacional Campesina $(C N C)$, de donde nacieron cuatro organizaciones: la Unión General de Obreros y Campesinos de México (UGOCM), la Central Campesina Independiente (cci), el Consejo Agrario Mexicano (CAM) y la Centra! Independiente de Obreros Agrícolas y Campesinos (CIOAC). Posteriormente, las tres primeras se incorporaron al partido político oficial (PRI), en tanto que la Central Independiente de Obreros Agrícolas y Campesinos siempre mantuvo ciertos laxos con los partidos de izquierda.
}

bros de la CNC y del PRI. NO está de más insistir en que si bien el modelo de control político era autoritario, también era incluyente, lo que significa que no dejaba fuera a los actores sociales del medio rural, sino que más bien le interesaba incorporarlos a la gobernación rural. Para lograr este objetivo, el gobierno recurría a organizaciones de campesinos de distinto nivel.

El primer nivel estaba constituido por las organizaciones corporativas, que recibían trato preferencial del Estado. En un comienzo, eran de carácter exclusivamente político, debido a los vínculos que tenían los comités ejecutivos de los ejidos con los comités regionales, las ligas estatales y la CNC. Sin embargo, en el decenio de 1970, cuando se realizó la primera enmienda sustantiva de la ley de reforma agraria en treinta años, ${ }^{22}$ la organización económica del ejido se convirtió en la forma de organización corporativa preferida. Esto condujo a la constitución de los primeros sindicatos ejidales y Asociaciones Rurales de Interés Colectivo en los años setenta. Como todas las formas de organización económica, debían responder a iniciativas del gobierno y se utilizaban como medios para facilitar la aplicación de los programas gubernamentales. Se desplegaron grandes esfuerzos para incorporar a la población rural a través de estos mecanismos. Nuevos tipos de organizaciones se crearon para incorporar a nuevos grupos. Así es como se establecieron las Unidades Agrícola-industriales de la Mujer en el decenio de 1970. En la década siguiente, se crearon, dentro del ejido, entre otras, las organizaciones de jóvenes, los Consejos Comunitarios de Abasto, y organizaciones especializadas en determinados productos. Dondequiera que aparecía una nueva meta nacional de importancia, una nueva demanda masiva en el campo, o un programa favorito de algún presidente, allí se creaba una nueva organización. Aunque no hubiera sido su propósito original, el establecimiento de esas organizaciones amplió la capacidad de negociación de los ejidos e hizo aparecer una nueva generación de líderes campesinos.

El segundo nivel de la organización campesina se basaba en organizaciones comunales tradicionales, que habían existido desde tiempos inmemoriales. Estas entidades, regidas por el principio de reciprocidad, ofrecían seguridad, trabajo colectivo y bolsas de mano de obra. En la mayoría de los ejidos, se adaptaron a las nuevas circunstancias, pero no desaparecieron.

\footnotetext{
22 Durante la presidencia de Luis Echeverría (1970-1976) se promulgó una nueva ley agraria.
} 
Como el criterio oficial para determinar si los campesinos estaban o no organizados era el número de organizaciones formales existentes, no se tomaban en cuenta estas organizaciones comunitarias, con lo cual se concluía que los campesinos no estaban organizados.

En el tercer nivel se encuentran las entidades que antes sólo tenían existencia teórica, porque habían sido creadas artificialmente por el gobierno, y que se convirtieron en organizaciones representativas. El proceso de transformación de instituciones comunitarias, formales e informales preexistentes - sindicatos ejidales, Asociaciones Rurales de Interés Colectivo y cooperativas- en organizaciones representativas obedeció a movilizaciones en defensa de causas específicas.

En gran medida, la coexistencia de estos distintos tipos de organizaciones campesinas fue consecuencia de una división de funciones no intencional. Las organizaciones gremiales establecían vínculos entre el Estado y los campesinos, y las comunitarias velaban por la solidaridad entre los miembros de la colectividad. Las organizaciones representativas surgieron cuando los cauces tradicionales de transmisión de demandas dejaron de funcionar.

\section{Los mercados secundarios como fuente de reproducción social}

Ningún modelo de control político es perfecto, sobre todo cuando no existe un plan preconcebido. Como el modelo fue evolucionando a medida que se aplicaba, muchos de sus aspectos son fruto del azar. Varios elementos del modelo se contradecían entre sí, y los instrumentos de control variaban de un gobierno a otro. Sin embargo, hubo dos componentes del modelo que no variaron. Su característica de inclusión se mantuvo, lo que significa que, en lugar de marginar a los nuevos agentes sociales y a los posibles disidentes, el Estado trataba de asimilar a cada grupo según las normas preestablecidas. También existía una fuerte ideología agraria, que actuaba como aglutinador de la estructura del ejido. Esta ideología se estructuraba en torno a dos grandes temas: i) la alianza entre los campesinos y el Estado, que supuestamente contribuiría al progreso de los primeros, y ii) la necesidad de recurrir a agentes del Estado como intermediarios entre los campesinos y el resto de la sociedad

Sin embargo, parece característico de todas las sociedades que cada intervención del Estado en la esfera política o en el mercado económico, sobre todo si se sostiene por un largo período, provoca una reacción contraria y da origen a mercados secundarios. El mo- delo de control estatal de los ejidos no fue una excepción a esta regla. Por ejemplo, la prohibición de vender tierras ejidales hizo aparecer un mercado secundario (Warman, 1980 y Gledhill, 1991). Las viudas y los ejidatarios que emigraban para no volver eran participantes primarios en las ventas de tierras; las fuentes primarias de la oferta eran la venta de terrenos excedentes o de parte de las parcelas de ejidatarios obligados a vender para hacer frente a crisis económicas. La prohibición de alquilar tierras hizo surgir un mercado ilegal aún más activo, sobre todo en las zonas de riego. Desde el punto de vista de los ejidatarios, el alquiler temporal de una parcela era un mecanismo de recuperación en casos de penuria económica. El alquiler ilegal de ejidos solía vincularse con la emigración de una zona a otra (De Walt, 1979). En algunos casos, el titular de la parcela se trasladaba por un largo período y la alquilaba para evitar que se le aplicara la prohibición de abandonar el ejido por más de dos años. En otros casos, un ejidatario viejo o su viuda arrendaban la parcela porque no tenían hijos que les ayudaran a trabajarla. También se podían contratar jornaleros para que remplazaran a los parientes que habían emigrado. La asamblea del ejido, que debía sesionar una vez al mes en presencia de un funcionario público, sesionaba frecuentemente sin cumplir ese requisito, aunque éste - a cambio de favores y beneficios - atestiguaba ex post facto haber estado presente. A veces, incluso se inventaban asambleas que nunca se habían realizado, con la anuencia del representante del gobierno. Así podían obtenerse créditos, seguros, caminos y escuelas. El método servía también para expulsar a ejidatarios, incorporar a nuevos miembros y despedir a integrantes de los comités ejecutivos.

Los mercados secundarios generaban sus propios agentes políticos y económicos: los dirigentes de los ejidos. Como todos los mercados negros son ilegales, estos agentes tenían que legalizar la transgresión de la ley. Por ejemplo, la venta de una parcela se legalizaba mediante un proceso de depuración y nuevas adjudicaciones. Aduciendo cualquier razón legal, el vendedor perdía su condición de ejidatario cuando se realizaba la venta, y el comprador pasaba a convertirse en nuevo ejidatario. Asimismo, se podía autorizar a un ejidatario a dejar de trabajar la tierra por más de dos años, alegando "razones de salud". Sin estos mecanismos, muchos dirigentes campesinos que habían abandonado el ejido hacía veinte o treinta años habrían perdido sus tierras. En algunos casos, un ejidatario no lo abandonaba oficialmente sino que prestaba la tierra "sin compensación" al comité ejecutivo o a una per- 
sona autorizada por el comité, aunque de hecho recibía dinero a cambio. Para el alquiler de tierras se aplicaba un mecanismo similar. Para ocultar la ausencia de un ejidatario, siempre se lo incluía en la lista de participantes en la asamblea. Además, su nombre figuraba en la nómina de créditos del banco oficial e incluso en la lista de personas aseguradas por la empresa estatal. Para compensar a los inquilinos por disponer de la tierra sólo por un corto período, debido a la ilegalidad de la transacción, los ejidatarios que alquilaban sus tierras los autorizaban a hacer uso de su nombre. En esta forma el arrendatario podía optar a los créditos oficiales subvencionados. En el noreste de México, algunos hacendados llegaron a alquilar no sólo parcelas, sino ejidos enteros.

Algunos de los mercados secundarios que surgieron a consecuencia de las intervenciones del Estado en la economía se convirtieron en negocios muy lucrativos. Por ejemplo, el negocio de los desastres consistía en la declaración de cosecha dañada, lo que permitía cobrar el seguro correspondiente. Para que el sistema funcionara, había que contar con la colaboración de un integrante del comité ejecutivo, que era el primero en ser notificado del "desastre". También había que contar con la complicidad de los representantes del Ministerio de Reforma Agraria y de la Secretaría de Agricultura y Recursos Hidráulicos, encargados de verificar el presunto desastre. También colaboraban en la notificación de desastre, los agentes de la empresa de seguros, los representantes del banco oficial y, por supuesto, el propio ejidatario. Este cobraba el seguro por "daño" a la cosecha, y luego la vendía a través de los conductos regulares del mercado. El ejidatario se compensaba así de los bajos precios de garantía o simplemente ganaba unos pesos más. ¿Qué recibían los demás participantes en la operación? Aquí es donde intervenía el agente del banco oficial. El ejidatario había recibido un préstamo pagadero en cuotas. La última cuota pagada antes del "desastre", se endosaba al agente, que cobraba el dinero y lo distribuía entre todos los colaboradores de esta peculiar operación (Relio, 1987).

En resumen, la reproducción del ejido se apoyaba en mercados secundarios o negros. Estos cumplían una notable función de adaptación de las intervenciones políticas y legales del Estado a la lógica que regía !a economía y la sociedad campesinas. Esta interacción entre dos racionalidades, muchas veces contradictorias, influyó en la forma de funcionamiento de ambas y las hizo compatibles, aunque no convergentes. Como es evidente, todo esto se logró a un enorme costo en términos de eficiencia y equidad, tanto por el derroche de recursos y carga para el erario público, como de los niveles de bienestar de los propios ejidatarios.

\section{IV}

\section{Reforma de la reforma agraria (1982-1994)}

\section{Convergencia de opuestos}

Las reformas del medio rural ejecutadas durante el gobierno del Presidente Salinas (1988-1994) se centraron en dos esferas fundamentales: la relación entre los productores rurales y el Estado y la relación entre los agentes productivos en el campo (Gordillo, 1992).

En los últimos 20 años, los campesinos desarrollaron mecanismos de resistencia a las políticas públicas en las zonas rurales. El Estado, con sus instrumentos de intervención y control, fue considerado cada vez más como un enemigo por los diferentes agentes sociales de las zonas rurales. Con frecuencia se politizaban los problemas económicos y provocaban confrontaciones que tenían efectos paradójicos. Las mismas políticas estatales que sofocaban a los ejidos los hacían reclamar un mayor apoyo estatal.
A raíz de la crisis de la deuda de 1982 y la posterior aplicación de políticas de estabilización y ajuste, dejó de ser económicamente viable la estrategia de desarrollo rural basada en un Estado omnipresente. El Estado había intervenido hasta entonces por muy distintos medios, incluso con subsidios específicos indirectos, regresivos en su mayor parte. Esta estrategia resultaba muy onerosa para el Estado, porque suponía el pago de cuantiosos subsidios, y en poco tiempo el modelo se volvió muy ineficiente. Los subsidios no sólo beneficiaban a los ejidos, sino también y sobre todo a la agricultura privada. Tenían propósitos variados: para el ejido, su objetivo era lubricar la maquinaria de control político; para el sector privado, se trataba de estimular la producción. A este último sector se le asignó la función clásica de la agricultura en un modelo de sustitución de importaciones: la producción 
de divisas y de alimentos baratos. La pérdida de eficiencia del modelo de control político se debió a que estaba concebido para una sociedad cerrada, dividida en segmentos corporativos. Los vientos de movilización política, que comenzaron a soplar con fuerza en México después del movimiento estudiantil de 1968, fueron erosionando este modelo autoritario. La legitimidad del Estado pasó a depender cada vez más del proceso electoral y de la apertura política. Por otra parte, la crisis de la deuda de 1982 también desarticuló el modelo económico prevaleciente en México desde los años cincuenta.

Por consiguiente, diminuyeron el control político y los subsidios económicos, lo que creó una coyuntura extraordinaria para la convergencia entre las políticas macroeconómicas de libre mercado y la movilización social. La política económica — cuyos pilares eran la liberalización del comercio, la desregulación y la privatización-y los objetivos de la movilización social, que perseguían la reestructuración de los mecanismos de representación del campesinado mediante la liberalización de políticas, coincidieron en sus críticas fundamentales a la intervención estatal. Esta convergencia no fue premeditada ni fomentada deliberadamente por el gobierno o la sociedad civil. Por el contrario, se suponía que la liberalización económica se lograría enmendando y usando el autoritarismo político, no eliminándolo. Así también, el objetivo de la estrategia de liberalización política, y en algunos casos de la democratización, era mantener los privilegios económicos derivados de los subsidios estatales.

¿Cómo llegaron a coincidir estas dos tendencias opuestas? Nunca hubo una política que combinara ambas estrategias. Lo que se dio en la práctica fue una yuxtaposición de políticas que produjo un vacío institucional. El modelo de control político dependía de la intervención estatal, pero muchas de las empresas estatales intervinientes se habían privatizado y sus controles se aflojaron cuando empezaron a tener problemas financieros. La clientela política apoyada por estas empresas impidió su completa privatización y los activos de muchas de ellas se transfirieron a productores rurales. Por ejemplo, los instrumentos básicos de control político en el campo se vieron afectados cuando el Banco Nacional de Crédito Rural (BANRURAL) entró en crisis financiera y cesó la distribución de tierras. Sin embargo, la oposición de los campesinos evitó la desaparición total del banco oficial y aparecieron así mecanismos alternativos, entre otros el crédito sin garantía del Programa Nacional de Solidaridad (PRONASOL) y, más recientemente, la creación de asociaciones de ahorro y préstamo. La oposición campesina también impidió que se suspendiera la distribución de tierras y permitió negociar en el caso de tierras que aún estaban en proceso de asignación. Esta convergencia tan particular hizo posible superar obstáculos, pero no se tradujo en la creación de instituciones.

Las reformas económicas tenían el doble propósito de poner fin al sistema de precios garantizados y de alinear los precios internos con los internacionales. No obstante, la yuxtaposición de ambas corrientes - la liberalización económica y la política- planteó dos graves problemas. En primer lugar, el sistema de precios de garantía - que cubría a 12 productos- desapareció, pero se mantuvo para el maíz y los frijoles. No hubo un plan de reajuste razonable para la alineación de precios y la apertura comercial, que modificaron en forma dramática la comercialización agrícola, e hicieron aumentar el endeudamiento de los campesinos. En cambio, el mantenimiento de los precios de garantía para el maíz y los frijoles dio utilidades extraordinarias a algunos productores. Todo el sector agrícola se volcó a la siembra de maíz, con lo cual evolucionó la agricultura hacia el monocultivo en vez de la diversificación.

La reforma del artículo 27 de la Constitución de México en 1991-1992 fue otro elemento del desmantelamiento del modelo de control político. Los propulsores del liberalismo económico la consideraban un medio adecuado para aprovechar el potencial productivo del ejido y crear un mercado de tierras. Para ejecutar sus planes, contaban con la eficacia del modelo de control político, sobre todo para aplicar las medidas más impopulares. Los partidarios del liberalismo político, por su parte, consideraban que las reformas legales desarticularían el modelo de control político, pero no el sistema de beneficios económicos paralelo. Las dos posiciones eran utópicas. La primera se centraba en la reducción de la intervención económica, manteniendo el control político, mientras la segunda propugnaba la reducción del control político y el mantenimiento de la intervención económica. La contradicción entre ambas creó graves lagunas institucionales, que si bien permitieron la aparición de un incipiente sistema campesino de producción, pusieron en grave peligro la eficacia de las reformas aplicadas.

\section{Una economía campesina trunca}

Luego de examinar las contradicciones y la complejidad del control político del ejido, cabe preguntarse cómo consiguió sobrevivir durante tanto tiempo. La 
respuesta, como ya se ha indicado, está en el papel del ejido como mecanismo de seguridad y como aparato político. A continuación, analizaremos la función desempeñada por el ejido como mecanismo de seguridad, vale decir, como órgano de representación de los campesinos. Esto se vincula estrechamente con el funcionamiento particular de una economía campesina. Es bien sabido que la economía campesina se basa en el hogar como unidad productora y de consumo, y en una serie de prácticas de asistencia recíproca entre los hogares de una colectividad. El ejido dio a la economía campesina una estructura institucional que vinculó estos dos elementos fundamentales con un tercero, igualmente importante: el acceso a recursos de propiedad colectiva.

Sin embargo, la aplicación concreta del modelo de control político distorsionó estos tres elementos. La adjudicación de parcelas al jefe de hogar y el hecho de que los demás integrantes del grupo familiar casi no tuvieran derechos legales, sembró la discordia entre ellos. En los últimos decenios, es evidente que se han generalizado las disputas familiares —entre padres e hijos, entre cónyuges y entre hermanos. Esta discordia se ha agudizado por efecto de la enorme transformación demográfica que ha sufrido el ejido, sobre todo a partir de los años setenta, y el ejido no ha tenido la flexibilidad necesaria para adaptarse. Los ejidatarios originales han envejecido, y muchos "avecindados" han llegado a las aldeas, en número que supera en algunos casos al de los ejidatarios, aunque no tienen derecho a ser considerados como tales. Otro factor importante ha sido la extensa migración al interior del país y a los Estados Unidos.

Las prácticas tradicionales de producción basadas en el empleo de semillas autóctonas, el control biológico, los fertilizantes orgánicos, la tracción animal y el cultivo intercalado se degradaron por efecto de un proceso trunco de modernización tecnológica iniciado por organizaciones gubernamentales dedicadas a la investigación y al desarrollo agrícolas. De hecho, hasta hace poco, expresamente se excluían los créditos para el cultivo intercalado, aunque éste es una de las piedras angulares de la agricultura campesina. Tampoco había normas claras sobre acceso a las tierras comunales. Esto no sólo llevó a apropiaciones ilegales, sino a una acelerada diferenciación social dentro del ejido y a una grave degradación de sus recursos naturales. Por todo ello, el sector ejidal se había convertido en una economía campesina trunca, que coexistía con el modelo estatal de control político, es decir una economía campesina agarrotada por el Estado. El ejido era tanto un aparato de control político del campesinado por parte del Estado como el órgano de producción y representación que permitía aplicar y perpetuar la lógica campesina. Se había logrado compatibilizar la lógica estatal y la lógica campesina, gracias a la existencia de mercados secundarios en los que se combinaban controles y subsidios, pero, como era inevitable, cuando este precario equilibrio comenzó a derrumbarse, el modelo de control político se vio decisivamente afectado.

Cuando se emplea el término "sistema campesino de producción" hay que precaverse de toda interpretación chayanoviana de este tipo de agricultura, como también de reabrir la antigua polémica sobre la extinción o la supervivencia del campesinado, que estaba muy en boga en los círculos académicos mexicanos en los años setenta. El sistema de producción campesina a que nos referimos aquí se caracteriza por su búsqueda de un medio de integración al sistema de mercado, posición basada en la ventaja comparativa de la agricultura del ejido frente a la agricultura privada. La agricultura ejidal tiene la ventaja de trabajar con mano de obra familiar y con una organización comunitaria, de tener acceso a recursos colectivos y fuerte participación en mercados laborales y, sobre todo, de contar con la migración nacional e internacional.

A continuación nos referiremos a las características fundamentales del sistema campesino de producción y cómo se desarrolló en el contexto de los cambios registrados en el ejido entre 1990 y 1994. Los resultados de la encuesta de ejidos realizada en 1994 por la Secretaría de la Reforma Agraria y la Universidad de California (Berkeley), comparados con los del estudio de la Secretaría de Agricultura y Recursos Hidráulicos (SAHR) y la CEPAL en 1990, son útiles para caracterizar las transformaciones sufridas por el sector en medio de la profunda crisis de todo el sector agrícola mexicano (de Janvry, Gordillo y Sadoulet, 1997). Esta crisis mayor se caracteriza por incentivos económicos adversos, un apoyo gubernamental en descenso, y grandes vacíos institucionales.

En la siguiente descripción del tamaño de los predios, la unidad de medida de las parcelas es la hectárea de equivalente nacional de tierras de secano (ENS), que corresponde al promedio de rendimiento del maíz de secano por zona agroecológica, a fin de ajustar la superficie según las diferencias de calidad de la tierra. La unidad de medida es una hectárea de maíz de secano, que produce 1.09 toneladas, es decir el promedio nacional de 1994. 
a) Concentración de la tierra en pequeñas explotaciones $^{23}$

Al clasificar a los ejidatarios de acuerdo con el tamaño de las parcelas y la zona geográfica se observa que entre 1990 y 1994 aumentó la proporción de pequeñas explotaciones en la mayoría de las regiones, con la excepción del Pacífico sur. Por lo tanto, se ha producido un lento proceso de eliminación de las formas más extremas de minifundio. Este hecho sugiere que una solución parcial al problema de la pobreza rural podría hallarse en el abandono de las explotaciones más pequeñas, ya sea por la migración a otras zonas agrícolas, o el trabajo en otros sectores. Varios aspectos de la reforma del ejido han incidido en su abandono. Uno es la reciente libertad que se otorga a los ejidatarios para alquilar tierras, lo que permite a los minifundistas alquilar su parcela y dedicarse a otras actividades. El otro factor es la mayor flexibilidad para participar en actividades no agrícolas y para emigrar sin peligro de perder el derecho a las tierras ejidales. El descenso del minifundio ha sido menos acelerado en las regiones del Golfo de México y del Pacífico sur, en que es más fuerte el apego del indígena a la tierra, y menos intensa la emigración a los Estados Unidos. En estas dos regiones, que registran la más alta incidencia de pobreza extrema, la solución no podrá provenir simplemente de la migración y el traspaso del problema de la pobreza a otros sectores y regiones.

\section{b) Consolidación del sistema de producción campe-} sina: el cultivo del maíz intercalado

Uno de los cambios más marcados del período 1990-1994 fue la expansión de la superficie sembrada con maíz, por efecto de la distorsión de precios que favoreció a este grano frente a otros cultivos y los precios de garantía que eliminaron el riesgo en su producción. Por lo tanto, el maíz ha sido un cultivo de gran interés en los últimos cuatro años. En el ejido, se ha aumentado en $20 \%$ el área sembrada de maíz en las tierras de secano y en $68 \%$ en las de riego. En las primeras, el $66 \%$ de la expansión corresponde al monocultivo, y el $34 \%$ restante a cultivos intercalados. El primero es característico de los predios con mayor vocación comercial; el segundo es típico del sistema campesino. La mayor parte del incremento (84\%) provino de predios de más de 5 ha ENS, en que se reemplazaron los pastizales o el barbecho por el maíz. En cambio, la mayor parte del aumento del maíz de cul-

23 Esta sección se basa en de Janvry, Gordillo y Sadoulet (1997). tivo intercalado $(72 \%)$ se dio en explotaciones pequeñas gracias al resurgimiento de sistemas de producción típicamente campesinos. En el caso de las tierras de riego, el 91\% de la expansión de las tierras dedicadas al cultivo de maíz se dio en predios grandes, en que desplazó a los cereales tradicionales, como el trigo y las oleaginosas, y el $97 \%$ correspondió al maíz en monocultivo. En las explotaciones más pequeñas, aumentó la producción de maíz en cultivo intercalado.

En las explotaciones agrícolas extensas, la ampliación correspondió sobre todo a un monocultivo comercial, fuente principal de la expansión total. Por lo tanto, los incentivos para fomentar el cultivo del maíz aceleraron el proceso de diferenciación, en que los predios más pequeños se han ido especializando cada vez más en sistemas campesinos de producción, mientras los de mayor tamaño se especializan en los sistemas comerciales.

\section{c) La regresión tecnológica}

Es evidente que en el período 1990-1994 hubo un grave retroceso tecnológico en el ejido que afectó a casi todos los aspectos y tipos de predios. En el caso del maíz, la única excepción es la difusión de semillas mejoradas en los predios más grandes. En lo demás, se produjo una acentuada disminución del uso de productos químicos y fertilizantes. La asistencia técnica gubernamental prácticamente cesó para todo el sector, cualquiera fuera el tamaño de la explotación. Paralelamente se registró un aumento general del trabajo manual en las labores agrícolas y descenso en el uso de maquinarias. En respuesta a la crisis de rentabilidad, el sector recurrió nuevamente a la mano de obra familiar, y aplicó menos tecnología por unidad de producción.

d) Marcada tendencia a la producción para autoconsumo

Para describir mejor la prevalencia de la economía campesina y la profundidad de la diferenciación social dentro del ejido, analizaremos el grado de participación de los ejidatarios en el mercado del maíz, ya sea como vendedores o compradores. El análisis muestra que el $41 \%$ son sólo vendedores o vendedores/compradores, en tanto que el $27 \%$ son sólo compradores. El $31 \%$ son productores autosuficientes, que destinan el maíz que producen principalmente para el consumo familiar (24\%) o para forraje (7\%). Esto muestra que hay una economía del maíz muy diferenciada, en que menos de la mitad de los productores participa en el mercado como vendedores. Si se llega 
a producir la baja prevista del precio del maíz con la entrada en vigor del Tratado de Libre Comercio de América del Norte, éste será el grupo de vendedores afectado. El 59\% restante no se verá afectado directamente o se beneficiará de la baja de los precios, por tratarse fundamentalmente de compradores netos. Esta categoría y la de productores autosuficientes sin gran- des hatos de ganado son agricultores con predios pequeños y poca tierra de riego. Así pues, la existencia de una economía campesina fuerte podría contrarrestar el efecto negativo de la baja del maíz, la que afectaría de distinta manera a las distintas categorías de hogares productores según su forma de integración al mercado.

\section{V}

\section{Algunas conclusiones para los próximos años}

La evolución registrada en el sector ejidal entre 1990 y 1994 estuvo marcada por los fenómenos siguientes:

- El impacto de las políticas macroeconómicas, caracterizadas por un control efectivo de la inflación, acompañado de una crisis de rentabilidad en la agricultura, vinculada con el descenso de las tasas mundiales de crecimiento económico, la creciente apreciación del tipo de cambio, la caída del precio mínimo real de garantía de los cultivos básicos, altas tasas de interés y suspensión de los subsidios.

- El vacío institucional creado por la decadencia de la ayuda estatal para la agricultura, que se tradujo en la privatización, la reducción o la eliminación de muchas instituciones públicas que prestaban apoyo al sector y en una muy limitada reconstrucción de la estructura institucional encargada de prestar asistencia al ejido. En general, esto dificultó y encareció la obtención de créditos, seguros, mercados, insumos modernos, semillas, agua y asistencia técnica.

- $\quad$ El despuntar de un proceso de ajuste de los ejidatarios y del ejido como forma de organización a las nuevas reglas económicas e institucionales.

Hacia 1994, las enmiendas de las disposiciones legales sobre el usufructo y dominio de la tierra ejidal habían dado ya un impulso al mercado de alquiler de tierras. Las reformas también facilitaron la iniciativa individual y comunitaria, lo que permitió numerosos ajustes del sistema productivo, de las estrategias de supervivencia de los hogares y de la organización del ejido, ajustes prohibidos antes de la reforma constitucional, por lo que algunos habían sido adoptados ilegalmente.

Así pues, entre 1990 y 1994, observamos un ejido en crisis, en las primeras etapas de un largo proce- so de adaptación y transformación. Las dificultades obvias que enfrentaban los ejidatarios eran en parte coyunturales y en parte estructurales, pero eran también síntoma de un proceso difícil y prolongado de liberalización económica y política.

Para concluir, advertimos que sería muy prematuro señalar qué efectos tendrá la segunda reforma agraria de México, iniciada por el Presidente Salinas. La liberalización del ejido ha dado lugar a numerosas iniciativas individuales y colectivas; los ajustes que éstas han producido demuestran la capacidad de responder a los incentivos de este vasto sector. A la vez, el contexto general de la crisis económica que ha afectado a la agricultura y la desinstitucionalización del sector rural han limitado los beneficios económicos que podría haber reportado la reforma y, por consiguiente, el alcance del proceso de modernización y diversificación que se esperaba de ella. El primer paso de la reforma - a saber, la titulación individual de las tierras ejidales en usufructo- apenas si ha comenzado. $\mathrm{Y}$ las consecuencias últimas de la reforma dependen de la resolución de problemas económicos y políticos mucho más amplios con los que México todavía está lidiando: por el lado económico, se trata de reanudar el proceso de crecimiento, mantener un tipo de cambio real competitivo y crear empleos; por el lado político, figuran el establecimiento de una democracia participativa, la descentralización del gobierno y la puesta en vigencia del imperio de la ley.

De lo que sí no podemos dudar es de que la segunda reforma agraria abre importantes posibilidades de mejorar la eficiencia y el bienestar de los ejidos. Los años de descuido y el cúmulo de contradicciones entre los objetivos que se le asignaban como aparato de control político del campesinado, órgano de representación y organismo de asistencia a los pequeños agri- 
cultores se han traducido en un enorme déficit de eficiencia, que ahora habrá que cubrir. El análisis de los casos de buen éxito ayudará a identificar las medidas que convendría adoptar (de Janvry, Gordillo y Sadoulet, 1997). Entre ellas figuran la creación de un clima macroeconómico favorable, la reconstrucción institucional, la promoción de organizaciones (sobre todo a través del sistema ejidatario) y las inversiones públicas para riego y educación. La iniciativa de reforma agraria debe complementarse con un programa integral de desarrollo rural que dé apoyo a los beneficiarios de la reforma, programa que aún queda por ejecutar, (de Janvry y otros, 1996). Por la notoria heterogeneidad de las unidades familiares campesinas, un programa de desarrollo rural destinado al ejido no debe limitarse a la agricultura, sino extenderse también a otras fuentes de ingreso al alcance de los ejidatarios. Esto implica la coordinación de intervenciones por todo un abanico de instituciones públicas y privadas. A menos que se to- men estas medidas rápidamente, la mayoría de los pequeños agricultores del sector ejidal probablemente no lleguen a ser competitivos, y correrán el riesgo de ser desplazados por unos pocos empresarios capaces, tanto del propio ejido como del sector privado, a medida que se afine el mercado de tierras. La falta de competitividad, por lo tanto, provocaría el desplazamiento masivo de minifundistas, y ejercería presiones sobre los mercados urbanos de trabajo y en la frontera al norte. En aras de la eficiencia económica global, del bienestar de una gran parte de los mexicanos pobres y de la estabilidad política, urge, pues, que la reforma agraria en marcha se complemente con un espectro más amplio de actividades, para ayudar a los beneficiarios de la reforma agraria a lograr la competitividad en el nuevo entorno económico e institucional antes de que termine el proceso de titulación y las reformas activen el mercado de venta de tierras.

(Traducido del inglés)

\section{Bibliografía}

Arispe Schloesser, L. (1985): Campesinado y migración, México D.F., Sep-Cultura.

Astorga, E. (1985): El mercado de trabajo rural en México, México D.F., Ed. Era.

Castillo, C.M. (1956): La economía agraria de El Bajío, Problemas agrícolas e industriales de México, vol. III, $\mathrm{N}^{\circ} 3-4$, México D.F., julio- diciembre.

Córdova, A. (1974): La política de masas del cardenismo, México D.F., Ed. Era,

(1973): La ideología de la revolución mexicana, México D.F., Ed. Era.

De Janvry, A., G. Gordillo y E. Sadoulet (1997): Mexico's Second Agrarian Reform, La Jolla, University of California, Center for US-Mexican Studies.

De Janvry, A., E. Sadoulet, B. Davis y G. Gordillo (1996): Ejido sector reforms: From land reform to rural development, en L. Randall (ed.), Reforming Mexico's Agrarian Reform, Nueva York, M.E. Sharpe.

De Janvry, A., E. Sadoulet, (1989): A study on resistance to institutional change: The lost game of Latín American land reform en World Development, vol. 17, $\mathrm{N}^{\circ}$ 9, Oxford, Reino Unido, Pergamon Press.

De Walt (1979): Modernization in a Mexican Ejido: A Study in Economic Adaptation, Cambridge, Massachusetts, Cambridge University Press,

Fernández y Fernández, R. (1973): Cooperación agrícola y organización económica de! ejido, México D.F., Secretaría de Educación Pública.

García Treviño, R. (1956): Agrarismo revolucionario y ejidalismo burocrático, Problemas agrícolas e industriales de México, vol. III, N 3-4, México D.F.

Gledhill, J. (1991): Casi Nada. A Study of Agrarian Reform in the Homeland of Cardenismo, Austin, Texas, University of Texas Press.
Gómez Olivier, L. (1978): Crisis agrícola de los campesinos. Revista de Comercio Exterior, vol, 28, № 6, México D.F., Banco Nacional de Comercio Exterior, junio.

Gordillo, G. (1988a): Campesinos ai asalto del cielo, México D.F., Siglo XXI Editores.

(1988 b): Estado, mercado y movimiento campesino, México D.F., Plaza y Valdés.

(1990): Reformando a la revolución mexicana, México D.F., El Nacional.

(1992): Más allá de Zapata, México D.F. Ed. Cal y Arena.

Hirschman, A.O. (1977): Salida, voz y lealtad, México D.F., Fondo de Cultura Económica,

Krauze, E. (1971): Caudillos intelectuales de la revolución, México, D.F., Editorial Siglo XXI.

Orozco, W. I. (1895): Legislación y jurisprudencia sobre terrenos baldíos, México D.F., El Tiempo.

Paré, I. (1977): El proletariado agrícola en México, México D.F., Siglo XXI Editores.

Prseworski, A. (1985): Capítalism and Social Democracy, Londres, Cambridge University Press.

Relio, F. (1987): State and Peasantry in México: A Case Study of Rural Credit in La Laguna, Ginebra, United Nations Research Institute for Social Development (UNRISD).

Torres, B. y L. Medina (1978): Historia de la revolución mexicana, ¡orno 18, México D.F., El Colegio de México.

(1979a): Historia de la revolución mexicana, tomo 19, México D.F., El Colegio de México.

(1979b): Historia de la revolución mexicana, tomo 20, México D, F., El Colegio de México.

Warman, A. (1980): Y venimos a contradecir, México D.F., La Casa Chata.

Whetten, N. (1948): Rural México, Chicago, Illinois, University of Chicago Press. 